\title{
Perfil Granulométrico da Fibra Dietética sobre o Tempo Médio de Retenção e a Digestibilidade Aparente de Dietas para Vacas Leiteiras
}

\author{
Edinaldo da Silva Bezerra ${ }^{1}$, Augusto César de Queiroz², Ana Raquel Gomes Faria Bezerra ${ }^{3}$, \\ José Carlos Pereira ${ }^{2}$, Mário Fonseca Paulino²
}

\begin{abstract}
RESUMO - Objetivou, com este experimento avaliar o efeito de diferentes tamanhos de partículas da fibra dietética sobre o tempo médio de retenção e a digestibilidade aparente de dietas para vacas leiteiras em lactação. Dez vacas holandesas com 550 kg de peso vivo médio foram distribuídas em um delineamento em switch back em três períodos consecutivos. Os animais foram estabulados individualmente e alimentados com rações em mistura completa, constituídas de feno de capim-Tifton (50,4\%) e concentrado (49,6\%). O feno foi triturado em moinho comercial com peneiras de malhas de 3,2; 4,8; 7,9; 15,9 e 25,4 mm. Amostras de cada moagem foram submetidas ao separador de partículas modelo Penn State, para determinação do perfil de distribuição das partículas de fibra. Constituiu-se cinco tratamentos: T1 - 100\% das partículas abaixo de $8 \mathrm{~mm}$; T2 - 76\% abaixo de 8 mm e 24\% entre 8 e 19 mm; T3 - 36,7\% abaixo de 8 mm, 26,6\% entre 8 e 19 mm e 36,7\% acima de $19 \mathrm{~mm}$; T4 - 32\% abaixo de $8 \mathrm{~mm}$, 28\% entre 8 e $19 \mathrm{~mm}$ e $40 \%$ acima de $19 \mathrm{~mm}$; T5 - 26\% abaixo de 8 mm, $28 \%$ entre 8 e 19 mm e $46 \%$ acima de $19 \mathrm{~mm}$. O perfil granulométrico exerceu efeito preponderante no trânsito das dietas, observando-se que aquelas com partículas de maior tamanho ficaram mais tempo no trato gastrintestinal. Os coeficientes de digestibilidade de matérias seca e orgânica foram maiores para dietas com menor granulometria comparativamente às de perfil mais grosseiro. Não houve efeito sobre as digestibilidades de proteína bruta e carboidratos não-fibrosos. A digestibilidade da fibra foi maior nas dietas com perfil mais fino. Os resultados sugerem que a granulometria da dieta pode ser determinante no tempo de retenção e na digestibilidade.
\end{abstract}

Palavras-chave: fibra efetiva, granulometria, taxa de passagem

\section{Dietary Fiber Particles Size on Retention Time and Apparent Digestibility Parameters in Dairy Cow Diets}

\begin{abstract}
The objective of this experiment was to evaluate the effects of different dietetic fiber physical effectiveness on the retention time and apparent digestibility of lactating dairy cows. Ten Holstein cows (average $550 \mathrm{~kg}$ of live weight) were allotted to a switch back experimental design in three successive periods. The animals were individually housed in a tie stall and fed with total mixed rations constituted by Tifton hay (50.4\%) and concentrated (49.6\%). The Tifton hay was ground in commercial miller with sieves with mesh of 3,2; 4,8; 7,9; 15,9 and 25,4 mm. Samples from each grinding were submitted to the Particles Separator Model Penn State for determination of profile distribution of the fiber particles. Five treatments were constituted: T1-100\% of particles below 8 mm; T2-76\% below $8 \mathrm{~mm}$ and 24\% from 8 to $19 \mathrm{~mm}$; T3-36.7\% below $8 \mathrm{~mm}$, 26.6\% from 8 to $19 \mathrm{~mm}$ and 36.7\% above 19 mm; T4-32\% below $8 \mathrm{~mm}$, 28\% from 8 to $19 \mathrm{~mm}$ and 40\% above $19 \mathrm{~mm}$; T5-26\% below $8 \mathrm{~mm}$, 28\% from 8 to $19 \mathrm{~mm}$ and $46 \%$ above $19 \mathrm{~mm}$. The fiber particle profile exercised effect on the retention time of the diets, being observed that those with larger particles size spend more time in the gastrointestinal tract. Dry matter and organic matter digestibility coefficients were higher for diets with smaller fiber particle size when compared to higher fiber particle size. There was not effect on the crude protein and nonfiber carbohydrate digestibilties. The digestibility of fiber was higher in the diets with finer fiber particle size. The results suggest that the fiber particle size of the diet could be decisive on the retention time and on the digestibility of the diets.
\end{abstract}

Key Words: effective fiber, granulosity, rate of passage

\section{Introdução}

A complexidade do aparelho digestivo dos animais ruminantes torna-os de grande valor econômico, em razão de seu potencial em aproveitar alimentos pouco usuais na alimentação de animais não-ruminantes e do homem. Embora haja necessidade de se trabalhar com sistemas de produção mais intensivos, em virtude da demanda crescente por proteína animal de qualidade pelos seres humanos e da redução de áreas agrárias, a dieta dos ruminantes ainda é baseada em quantidades relativamente altas de forragens, que são ricas em

\footnotetext{
${ }^{1}$ Universidade Federal Rural-RJ, km 7 BR465, CEP: 23890-000, Seropédica - RJ (naldobezerra@uol.com.br).

2 Universidade Federal de Viçosa, Viçosa - MG.

3 IBAMA - RJ.
} 
fibra em detergente neutro (FDN). Isto decorre não somente do fato de esses animais ainda dependerem dos efeitos físicos e fisiológicos da fibra no trato gastrointestinal, mas também da significativa redução nos custos com a dieta que esses alimentos podem representar dentro de um programa de alimentação.

Dietas com altos níveis de FDN podem, de fato, significar redução nos custos com alimentação, mas podem promover restrições ao consumo alimentar, pela necessidade de maior tempo de permanência do alimento no rúmen para que possa sofrer o devido processo de digestão, o que pode limitar a exploração econômica em sistemas de produção mais intensivos, onde a demanda nutricional é mais elevada.

No rúmen, o crescimento microbiano é função, primeiramente, da quantidade e da taxa de digestão de carboidratos no rúmen (Hoover \& Stokes, 1991), pois vários estudos (Mccarthy et al., 1989; HerreraSaldaña et al., 1991; Aldrich et al., 1993) têm demonstrado que ele aumenta com o fornecimento de carboidratos de fácil fermentação, em comparação ao uso de carboidratos de fermentação lenta. Entretanto, a redução do $\mathrm{pH}$, como conseqüência do uso de carboidratos de fermentação rápida, é considerada um dos principais fatores a influenciar o crescimento (Sniffen \& Robinson, 1987) e a composição (Ishler et al., 1996) da microbiota ruminal.

As bactérias precisam de um tempo de geração menor que a taxa de turnover da digesta ruminal para que a população possa ser mantida no rúmen (Church, 1988). Uma vez que a taxa de passagem da fase sólida é muito menor que a da fase líquida no rúmen, as espécies de crescimento lento têm de se aderir às partículas do material para que não sofram lixiviação e remoção do rúmen (Van Soest, 1994). Este fato tem especial importância para dietas à base de forragens, cujo tempo de permanência no rúmen é maior. A maior permanência facilita a colonização e a digestão da parede celular (Bondi, 1988), tornando a taxa de passagem importante fator para o crescimento microbiano.

A taxa de passagem da digesta pelo trato gastrintestinal tem significativo efeito sobre a degradação ruminal da fibra (Firkins, 1997), especialmente em animais de alto desempenho. Quanto maior a taxa de passagem, menor a degradabilidade da FDN, principal responsável por fornecer energia para suportar o crescimento microbiano no rúmen em dietas com alta proporção de volumoso. Por outro lado, o aumento da taxa de passagem também pode estimular a eficiência de síntese microbiana, graças à redução da energia gasta para mantença dos microrganismos (Russell et al., 1992; Firkins, 1996).

A saída das partículas alimentares do retículorúmen é determinada, principalmente, pelo tamanho e pela densidade dessas partículas (Kaske \& Von Englehardt, 1990; Weidner \& Grant, 1994), que estão, por sua vez, intrinsecamente associados à degradabilidade do alimento oferecido. O destino do alimento é determinado, em última análise, pelas taxas de fermentação e de passagem (Waldo \& Smith, 1972). A taxa de fermentação é uma propriedade inerente ao alimento, enquanto a taxa de passagem pode ser regulada pelaingestão dealimento, peloprocessamento ou pelo tamanho da partícula e pelo tipo de alimento que está sendo consumido (Russell et al., 1992).

A interação entre fermentação e passagem, entretanto, é bastante complexa e muitos pesquisadores vêm tentando desenvolver modelos matemáticos sobre esses processos dinâmicos que ajudem a compreender melhor a atividade gastrintestinal e a eficiência digestiva. É importante observar que o crescimento microbiano é essencialmente limitado pela taxa de fermentação, que, por sua vez, é limitada pela composição e estrutura do alimento oferecido (Van Soest, 1994), especialmente no que concerne à quantidade e qualidade da fibra presente nesse alimento.

Este trabalho foi conduzido com o propósito de avaliar a digestibilidade e a taxa de passagem de dietas contendo diferentes perfis granulométricos, formuladas para vacas em lactação, com as mesmas proporções de concentrado e de volumoso.

\section{Material e Métodos}

O trabalho com os animais foi desenvolvido no Setor de Bovinocultura de Leite do Departamento de Zootecnia (DZO) da Universidade Federal de Viçosa (UFV), em Viçosa - MG. Os trabalhos de incubação em líquido de rúmen de sobras e alimentos foram realizados no Instituto de Zootecnia (IZ) da Universidade Federal Rural do Rio de Janeiro (UFRRJ) e as análises químicas e bromatológicas foram feitas nos Laboratórios de Nutrição Animal do DZO e do IZ e no Laboratório de Análise de Nitrogênio do Centro Nacional de Pesquisa em Agrobiologia (CNPAB) da EMBRAPA, Seropédica - RJ. 
Foram utilizadas dez vacas holandesas com grau de sangue entre $7 / 8$ e PC entre a segunda e a quinta ordem de lactação, com peso vivo inicial variando de 450 a $650 \mathrm{~kg}$, todas já tendo atingido o pico de lactação. Foi utilizado o delineamento em switchback, conforme preconizado por Lucas (1960), com dez vacas distribuídas em dois blocos, adotando-se a ordem de parição como variável restritiva para composição dos blocos. As vacas foram alojadas em baias individuais tipo tie stall, dotadas de comedouros e bebedouros individuais.

Os dados foram coletados durante três períodos consecutivos de 28 dias (14 dias de adaptação dos animais às dietas e 14 dias de coleta de dados). Para compor os tratamentos, o feno foi submetido à desintegração em moinho comercial de facas, dotado de peneiras com malha de 3,2; 4,8; 7,9; 15,9 e 25,4 mm. Aproximadamente $100 \mathrm{~g}$ de amostra do material triturado em cada peneira foram colocados em separador de partículas modelo Penn State, de acordo com a metodologia proposta por Lammers et al (1996) e em consonância com os procedimentos sugeridos pela ADSA (1970) para determinação do perfil granulométrico da dieta. Os tratamentos foram constituídos segundo o perfil da fibra de cada material resultante das peneiras de moagem (Tabela 1 ).

Foram utilizadas dietas isonutricionais completas composta por feno de Tifton e suplemento concentrado elaborado com milho e soja, para todos os animais (Tabela 2). As exigências nutricionais foram estabelecidas com base nas recomendações do NRC (1988).

Para determinar o tempo médio de retenção, empregou-se a metodologia descrita por Uden et al. (1980), fazendo-se a complexação da fibra do feno com cromo mordante. As amostras de fezes destina-

Tabela 1- Perfil de distribuição (\%) das partículas de fibra nos tratamentos

Table 1 - Fiber distribution profile (\%) in the treatments

\begin{tabular}{lrrrr}
\hline \multirow{2}{*}{$\begin{array}{l}\text { Tamanho das partículas } \\
\text { Size of the particles }\end{array}$} & \multicolumn{3}{c}{$\begin{array}{c}\text { Tratamento } \\
\text { Treatment }\end{array}$} \\
\cline { 2 - 5 } & \multicolumn{1}{c}{$\mathrm{T} 1$} & $\mathrm{~T} 2$ & $\mathrm{~T} 3$ & $\mathrm{~T} 4$ \\
\hline Acima de 19 mm (Above 19 mm) & 0,0 & 0,0 & 36,7 & 40,0 \\
Entre 8 e 19 mm (From 8 to 19 mm & 0,0 & 24,0 & 26,6 & 28,0 \\
Acumulado ( 8 mm) (Accumulated, $\geq 8 \mathrm{~mm}$ ) & 0,0 & 24,0 & 63,3 & 68,0 \\
Abaixo de 8 mm (Below 8 mm) & 100,0 & 76,0 & 36,7 & 32,0 \\
Acumulado total (Total accumulated) & 100,0 & 100,0 & 100,0 & 100,0 \\
\hline
\end{tabular}

Foram utilizadas dietas isonutricionais completas constituídas por feno de tifton e suplemento concentrado, elaborado com milho e soja para todos os animais (Tabela 2). As exigências nutricionais foram estabelecidas com base nas recomendações do NRC (1988). Isonutritional complex diets with Tifton hay and supplement (corn and soybean) was fed to all animals (Table 2). The nutritional requirements were established according to NRC (1988).

Tabela 2 - Composição percentual ${ }^{1}$ do concentrado e da dieta total (\%)

Table 2 - Composition ${ }^{1}$ of the concentrated ration and total mix ration (\%)

\begin{tabular}{lcc}
\hline $\begin{array}{l}\text { Ingredientes } \\
\text { Feeds }\end{array}$ & $\begin{array}{c}\text { Concentrado } \\
\text { Concentrate ration }\end{array}$ & $\begin{array}{c}\text { Dieta total } \\
\text { Total mix ration }\end{array}$ \\
\hline Milho moído (Ground corn) & 59,0 & 29,26 \\
Farelo de soja (Soybean meal) & 35,0 & 17,36 \\
Calcário (Limestone) & 1,9 & 0,94 \\
Fosf. bicálcico (Dicalcium phosphate) & 1,1 & 0,55 \\
Sal(Salt) & 1,0 & 0,50 \\
Supl. vitamínico (Premix vitamin) & 1,0 & 0,50 \\
Supl. mineral (Premix mineral) & 1,0 & 0,50 \\
Feno (Hay) & - & 50,40 \\
\hline
\end{tabular}

${ }^{1}$ Expressa na matéria seca.

${ }^{1}$ Expressed on dry matter.

R. Bras. Zootec., v.33, n.6, p.2378-2386, 2004 (Supl. 3) 
das à determinação do teor de cromo foram preparadas de acordo com a metodologia sugerida por Williams et al. (1962). A concentração de cromo nas fezes foi determinada em espectrofotômetro de absorção atômica, utilizando-se a metodologia descrita por Silva (1990).

Amostras dos ingredientes foram analisadas no Laboratório de Nutrição Animal da UFV para determinação da composição nutricional (Tabela 3). As rações foram calculadas com auxílio do pacote computacional Pudairy, desenvolvido pela Purdue University.

As dietas totais foram pesadas diariamente e oferecidas ad libitum duas vezes ao dia, pela manhã e à tarde, imediatamente antes das ordenhas. A quantidade da mistura total foi ajustada no período de adaptação para garantir sobras de, aproximadamente, $10 \%$ do oferecido. As sobras foram retiradas sempre antes da primeira alimentação da manhã.

Amostras da ração e do feno foram coletadas, embaladas em sacos plásticos devidamente identificados e armazenadas em freezer para análises laboratoriais posteriores. Após o descongelamento, foram secas em estufa ventilada a $65^{\circ} \mathrm{C}$ por 72 horas, para se proceder a moagem. Ingredientes da ração e o material seco em estufa foram moídos em moinho tipo Willey, com peneira de 1,0 mm, acondicionados em vidros com tampas e armazenados para posterior análises laboratoriais.

Os materiais foram analisados em laboratório para avaliação do conteúdo em matéria seca (MS), fibra em detergente ácido (FDA) e nitrogênio total (N) pelas metodologias descritas por Silva (1990).

A fibra em detergente neutro (FDN), a lignina, o nitrogênio insolúvel em detergente neutro (NIDN) e o nitrogênio insolúvel em detergente ácido (NIDA) foram determinados pelas metodologias propostas por Van Soest et al. (1991). Para acessar a FDN indigestível, utilizou-se o método adaptado de Pell \& Schofield (1993). Teores de cinzas e extrato etéreo bruto foram determinados pela metodologia do AOAC (1990). O teor em carboidratos não-fibrosos (CNF) foi estimado por diferença, adotando-se a seguinte equação (Van Soest et al., 1991): CNF $=100-[\mathrm{N}$ total $\times 6,25+$ Cinzas + Extrato Etéreo + (FDN NIDN $\times 6,25)]$

Para determinação dos coeficientes de digestibilidade da matéria seca e dos demais nutrientes, foi empregada a técnica do indicador interno, tendo a FDN indigestível como fator de referência. Foram coletadas amostras de fezes diretamente no reto, pela manhã e à tarde em três dias alternados durante o período de coleta. As amostras de fezes foram acondicionadas em sacos plásticos, identificadas e armazenadas em freezer para posterior processamento. O preparo da amostra composta foi realizada após pré-secagem e moagem do material.

Os resultados de digestibilidade foram analisados de acordo com o seguinte modelo estatístico:

$$
\mathrm{Y}_{\mathrm{ijkl}}=\mu+\mathrm{A}_{\mathrm{i}}+\mathrm{P}_{\mathrm{j}}+\mathrm{T}_{\mathrm{k}}+\mathrm{B}_{\mathrm{l}}+\varepsilon_{\mathrm{ijkl}}
$$

em que $\boldsymbol{Y}_{\boldsymbol{i k} \boldsymbol{k} j}$ é o dado referente ao i-ésimo animal, no j-ésimo período, do k-ésimo tratamento; $\mu$, a média geral observada; $\boldsymbol{A}_{\boldsymbol{i}}$, o efeito do i-ésimo animal; $\boldsymbol{P}_{\boldsymbol{j}}$, o efeito do j-ésimo período, $\boldsymbol{T}_{\boldsymbol{k}}$, o efeito do k-ésimo tratamento; $\boldsymbol{B}_{l}$, o efeito l-ésimo bloco; e $\boldsymbol{\varepsilon}_{i j k}$, o erro aleatório associado ao i-ésimo animal, do j-ésimo período do k-ésimo tratamento. Os valores médios foram comparados pelo teste de Student Newman Keuls e a análise estatística foi realizada usando-se o SAEG Sistema de Análises Estatísticas (UFV, 1995).

Tabela 3 - Composição bromatológica da dieta total e de seus ingredientes (\%)

Table 3 - Chemical composition of the total mix ration and ingredients (\%)

\begin{tabular}{|c|c|c|c|c|c|c|c|}
\hline \multirow[t]{3}{*}{ Item } & \multirow[t]{3}{*}{$\begin{array}{l}\text { MS } \\
D M\end{array}$} & \multicolumn{6}{|c|}{$\begin{array}{l}\text { Na matéria seca } \\
\text { In dry matter }\end{array}$} \\
\hline & & $\mathrm{PB}$ & FDN & FDA & $\mathrm{EE}$ & $\mathrm{MO}$ & CNF \\
\hline & & $C P$ & $N D F$ & $A D F$ & $E E$ & $O M$ & NFC \\
\hline Milho moído (Ground corn) & 87,93 & 7,46 & 31,01 & 1,42 & 4,15 & 98,35 & 55,72 \\
\hline Farelo de soja (Soybean meal) & 85,56 & 42,62 & 9,35 & 7,82 & 1,95 & 94,61 & 40,69 \\
\hline Feno (Hay) & 92,76 & 4,75 & 62,33 & 32,50 & 0,76 & 94,75 & 26,90 \\
\hline Concentrado (Concentrated ration) & 87,76 & 19,35 & 21,73 & 3,59 & 3,15 & 91,63 & 47,40 \\
\hline Dieta total (Total mix ration) & 90,26 & 12,05 & 42,03 & 18,22 & 1,96 & 93,19 & 37,15 \\
\hline
\end{tabular}

R. Bras. Zootec., v.33, n.6, p.2378-2386, 2004 (Supl. 3) 
Para determinação dos parâmetros de trânsito da digesta, as curvas de concentração de cromo foram ajustadas ao modelo exponencial bicompartimental G2G1 proposto por Pond et al. (1988), conforme apresentado a seguir.

$$
\mathrm{Y}=\mathrm{C} 2[\delta 2 \mathrm{e}-\mathrm{k} 2(\mathrm{t}-\mathrm{TT})-\mathrm{e}-\lambda 1(\mathrm{t}-\mathrm{TT})(\delta 2+\delta \lambda 1 \mathrm{t})]
$$

em que: $\mathrm{Y}$ representa a concentração fecal do marcador em determinado tempo; C2, a concentração inicial do marcador; k2, a taxa para os tempos de permanência com distribuição exponencial; t, o tempo após dosagem do cromo; TT, o tempo de trânsito; $\lambda 1$, a taxa para os tempos de permanência com distribuição gama; e $\delta=\lambda 1 /(\lambda 1-\mathrm{k} 2))$.

O tempo médio de retenção (TMR) foi calculado como segue:

$$
\mathrm{TMR}(\mathrm{h})=\mathrm{TR} 1+\mathrm{TR} 2
$$

em que TR1 $=2 / \lambda 1+1 / \mathrm{k} 2$; e TR2 $=$ TT.

Os parâmetros da cinética de degradação ruminal foram estimados por meio da aplicação de modelos matemáticos, utilizando-se os procedimentos sugeridos por Vieira (1995) e empregando o procedimento REGMRQ do SAEG - Sistema de Análises Estatísticas (UFV, 1995).

\section{Resultados e Discussão}

O tempo médio de retenção (TMR) de cada dieta e os resultados de digestibilidade da matéria seca (DMS), da matéria orgânica (DMO), da proteína bruta (DPB), da fibra em detergente neutro (DFDN), da fibra em detergente ácido (DFDA) e dos carboidratos não-fibrosos (DCNF) podem ser observados na Tabela 4.

A análise dos dados revelou efeito significativo $(\mathrm{P}<0,05)$ do perfil granulométrico da dieta sobre o tempo médio de retenção das partículas dietéticas. O maior tempo de permanência foi observado na dieta com maior proporção de partículas mais grosseiras, verificando-se que as partículas da dieta com menor perfil granulométrico permaneceram por tempo menor no trato gastrintestinal. Os resultados são compatíveis com os verificados na literatura (Dixon \& Milligan, 1985), que demonstram claramente ser o tamanho da partícula dietética um dos principais fatores a determinar a velocidade de trânsito da digesta no trato gastrintestinal.

A dinâmica de partículas, especialmente a degradação e o escape, é uma das principais características da digestão ruminal, mas, de fato, pouco progresso tem sido feito nessa área, face às dificuldades metodológicas (Sauvant, 1997). Contudo, os estudos de modelagem têm apresentado algumas proposições com relação aos aspectos dinâmicos.

À medida que entram no rúmen, as partículas alimentares são distribuídas conforme seu tamanho e a sua densidade, e a forma como se dá essa distribuição depende do tamanho do corte ou da moagem do alimento processado, do teor de umidade, da composição química e da atividade de mastigação pelo animal (Allen \& Mertens, 1988). Partículas de tamanho superior a um determinado limite terão que ser reduzidas antes de escaparem do rúmen-retículo, sendo esse limite bastante variável. A partir da análise fecal, tem-se postulado que as partículas alimentares maiores que 2,0 mm para ovinos e 4,0 mm para bovinos tem baixa probabilidade de deixarem o rúmenretículo (Poppi et al., 1980; Des Bordes \& Welch, 1984; Allen \& Mertens, 1988; Kaske \& Von Engelhardt, 1990).

Poppi et al. (1980) propuseram a "teoria do tamanho crítico”, na qual a retenção de partículas no rúmen-retículo é dependente do tamanho dessas partículas. Sauvant (1997) relatou que a proporção de partículas de determinado tamanho, obtida num bolo alimentar ingerido, guarda correlação positiva com a mesma proporção medida em determinada dieta, e sugeriu que o fluxo de partículas ruminais é dependente do tamanho da partícula, do conteúdo em parede celular dietética, da fração indigestível da dieta e do peso vivo do animal. Esta observação é confirmada pelos resultados apresentados neste estudo, no qual as dietas com proporção de partículas de maior tamanho ficaram mais tempo retidas no trato gastrointestinal.

Dixon \& Milligan (1985) verificaram que a velocidade do fluxo da digesta no trato gastrointestinal de ovinos foi influenciada pelo tamanho e pela densidade da partícula de feno, com o maior tempo de permanência associado às dietas que apresentavam maior tamanho da partícula e menor densidade. O mesmo padrão foi observado por Kaske \& Von Engelhardt (1990).

Os coeficientes de digestibilidade da matéria seca e da matéria orgânica foram significativamente afetados $(\mathrm{P}<0,05)$ pelas mudanças no perfil da fibra. A 
dieta cujo perfil da fibra tinha a menor granulometria foi a que apresentou maior coeficiente, enquanto a dieta de perfil granulométrico mais grosseiro foi a que apresentou menor coeficiente de digestibilidade.

Dois aspectos associados ao tamanho da partícula poderiam ser responsabilizados pelos resultados de digestibilidade: área de superfície de contato e densidade das partículas alimentares no trato gastrointestinal.

A área de superfície das partículas pode ser um dos principais determinantes no processo de colonização e, conseqüentemente, na digestão enzimática microbiana no rúmen (Fisher et al., 1989; Sauvant, 1997). A adesão é uma estratégia empregada pelos microrganismos para melhor utilizarem o substrato ao qual se aderem e, principalmente, evitarem a remoção por lavagem, decorrente do fluxo digestivo (Flint \& Forsberg, 1995). Essa adesão é feita por vários mecanismos; mas, de acordo com Yokoyama \& Johnson(1988), os organismos celulolíticos ruminais se utilizam principalmente do glicocálix emitido, sobretudo nas bordas dos pontos que apresentam algum tipo de ruptura promovida por processos mecânicos (mastigação, processamento etc).

Se as partículas são finamente moídas, com menor número de pontos de adesão, pode ocorrer inibição do crescimento microbiano por lavagem antes que o devido processo de colonização se instale (Van Soest, 1994). Portanto, quanto menor o tamanho da partícula do substrato a que os microrganismos estão se aderindo, menores e em menor número são os pontos disponíveis para adesão e mais difícil é o processo de colonização, com conseqüente queda na digestibilidade do substrato.

A influência da densidade também está associada ao processo de colonização microbiana. Neste caso, é preciso entender o rúmen como um sistema multicompartimentado, implicando em microrganismos livres no fluido ruminal, microrganismos associados com a parede ruminal e microrganismos aderidos às partículas alimentares (Cheng \& Mcallister, 1997).

Partículas menos densas, em geral associadas à massa sólida de digesta, formam uma espécie de esteira ruminal, que sofre colonização e digestão pela ação de enzimas microbiológicas. A ação microbiana favorece a redução do tamanho da partícula, aumentando seu peso relativo, o que faz com que se desprenda da massa, ficando em suspensão no líquido ruminal. Os microrganismos livres no compartimento líquido vão favorecer a redução da partícula suspensa até que ela fique passível de remoção do sistema ruminorreticular. A digestão da fibra dietética no rúmen impõe a necessidade de maior tempo de permanência para a colonização (NRC, 1988). Se as partículas são muito pequenas, serão rapidamente lavadas e removidas do rúmen-retículo e não sofrerão a devida ação biológica.

Vistos sob a ótica anteriormente exposta, os resultados aqui encontrados seriam contraditórios, pois justamente as dietas constituídas de partículas maiores foram as que apresentaram menor digestibilidade. Todavia, outros fatores tão ou mais importantes que o tamanho e a densidade das partículas também podem responder pela maior ou menor

Tabela 4 - Tempo médio (h) de retenção (TMR) e valores médios (\%) de digestibilidade aparente da matéria seca (DMS), da matéria orgânica (DMO), da proteína bruta (DPB), da fibra em detergente neutro (DFDN), da fibra em detergente ácido (DFDA) e dos carboidratos não-fibrosos (DCNF) das dietas

Table 4 - Retention time average (RTA) and apparent digestibility values (\%) of dry matter (DMD), organic matter $(O M D)$, crude protein (CPD), neutral detergent fiber (NDFD), acid detergent fiber ( $A D F D)$, and non fiber carbohydrates (NFCD) of the diets

\begin{tabular}{lcccccr}
\hline $\begin{array}{l}\text { Parâmetros } \\
\text { Parameters }\end{array}$ & \multicolumn{7}{c}{$\begin{array}{c}\text { Tratamento }^{1} \\
\text { Treatment }^{1}\end{array}$} \\
\cline { 2 - 6 } & \multicolumn{7}{c}{1} & 2 & 3 & 4 & 5 & CV \\
\hline TMR (RTA) & $46,87^{\mathrm{b}}$ & $52,56^{\mathrm{ab}}$ & $58,90^{\mathrm{ab}}$ & $57,43^{\mathrm{ab}}$ & $63,15^{\mathrm{a}}$ & 13,93 \\
DMS (DMD) & $70,20^{\mathrm{a}}$ & $63,93^{\mathrm{ab}}$ & $62,93^{\mathrm{ab}}$ & $68,87^{\mathrm{a}}$ & $58,75^{\mathrm{b}}$ & 9,25 \\
DMO (OMD) & $70,90^{\mathrm{a}}$ & $64,84^{\mathrm{b}}$ & $64,07^{\mathrm{b}}$ & $69,62^{\mathrm{a}}$ & $59,77^{\mathrm{b}}$ & 8,96 \\
DPB (CPD) & 73,46 & 70,29 & 69,27 & 70,15 & 63,37 & 11,01 \\
DFDN (NDFD) & $67,64^{\mathrm{a}}$ & $58,06^{\mathrm{b}}$ & $58,31^{\mathrm{b}}$ & $66,58^{\mathrm{a}}$ & $58,71^{\mathrm{b}}$ & 7,57 \\
DFDA (ADFD) & $61,12^{\mathrm{a}}$ & $49,74^{\mathrm{b}}$ & $47,26^{\mathrm{b}}$ & $60,52^{\mathrm{a}}$ & $48,98^{\mathrm{b}}$ & 9,62 \\
DCNF (NFCD) & 73,51 & 70,43 & 68,39 & 72,54 & 59,42 & 13,24 \\
\hline
\end{tabular}

${ }_{1}^{1}$ Médias na linha, seguidas de letras distintas, diferem significativamente entre si $(P<0,05)$.

${ }^{1}$ Means in line, followed by different letter, are significantly different $(P<.05)$.

R. Bras. Zootec., v.33, n.6, p.2378-2386, 2004 (Supl. 3) 
digestibilidade da matéria seca e da matéria orgânica. De fato, a mastigação durante a alimentação e a ruminação promovem quebra nas barreiras estruturais do alimento resistentes à digestão, como cutículas nas forragens e no pericarpo nos grãos, e expõe os tecidos internos ricos em nutrientes à colonização microbiana (Beauchemin et al., 1994). Até certo ponto, o processamento de forragens pode ter um efeito semelhante, uma vez que a desintegração das partículas alimentares poderia, em princípio, aumentar a superfície relativa, permitindo que as enzimas tenham mais área de contato e, desta forma, favoreçam a ação microbiana (Buxton \& Redfearn, 1997).

Não houve efeito do perfil granulométrico das dietas sobre a digestibilidade da proteína bruta e dos carboidratos não-fibrosos. Da composição das dietas e de seus ingredientes, pode-se concluir que os ingredientes concentrados foram responsáveis por praticamente metade da matéria seca da dieta consumida pelos animais. Com a baixa concentração protéica do feno, o concentrado foi responsável pela maior parte do suprimento de proteína aos animais. Como esses alimentos são, reconhecidamente, de elevada digestibilidade, não é surpresa que o perfil da fibra não tenha exercido influência sobre a digestibilidade daquele nutriente.

Enfoque semelhante pode ser dado ao fato de digestibilidade dos carboidratos não-fibrosos também não ter sido influenciada pelo aumento da efetividade da fibra das dietas. Afinal, com pouco mais de $20 \%$ de carboidratos não-fibrosos em sua composição, o feno contribuiu com menos de $10 \%$ da oferta desses carboidratos na dieta dos animais e, portanto, seria pouco provável um efeito direto significativo da efetividade da fibra desse ingrediente sobre a digestibilidade dos carboidratos de reserva.

Embora, em termos absolutos, as médias de digestibilidade dos carboidratos não-fibrosos pareçam discrepantes entre os tratamentos, o fato de a análise estatística não ter revelado contraste significativo pode estar relacionado a um elevado coeficiente de variação, o que reduziu as chances de se identificar diferenças mínimas significativas.

Os valores comprovaram que a digestibilidade da fibra em detergente neutro e da fibra em detergente ácido são sensíveis $(\mathrm{P}<0,05)$ à variação do perfil granulométrico das dietas. A exemplo do que ocorreu com a matéria seca e com a matéria orgânica, maiores valores de digestibilidade foram apresentados pela dieta cujas partículas tinham perfil mais fino, enquanto os animais submetidos às dietas caracterizadas por perfil granulométrico mais grosseiro foram os que menos digeriram a fibra dietética.

Existem poucos dados na literatura para ilustrar o efeito da efetividade física e do perfil granulométrico da dieta sobre a digestibilidade, especialmente sobre os nutrientes da ração, até porque o conceito de efetividade da fibra, do ponto de vista físico, é relativamente recente. Mooney \& Allen (1997), todavia, verificaram que o tamanho da partícula de silagem não teve efeito sobre a taxa e a degradação da fibra. Normalmente, espera-se que o aumento relativo do tamanho da partícula na dieta promova maior digestibilidade da fibra (Mertens \& Loften, 1980; Uden, 1992), em razão do maior tempo de permanência da partícula no rúmen.

Sabe-se que existe uma relação inversa entre as taxas de passagem e de digestão da fibra no rúmen (Allen \& Mertens, 1988), de maneira que qualquer fator que possa afetar o tempo de permanência de partículas alimentares no rúmen poderá ter efeito sobre a digestibilidade do alimento. Um exemplo típico, já mencionado neste trabalho, é o da área de superfície das partículas alimentares, que, quando aumentada por moagem, pode elevar a taxa de digestão, graças ao melhor acesso das enzimas microbianas.

A taxa de passagem mais rápida deveria ter contribuído para que as dietas com maior proporção de partículas mais grosseiras apresentassem menor digestibilidade da fibra, como observado por Firkins (1997). Uma possível explicação é que, embora a maior digestibilidade possa expor mais nutrientes à síntese protéica microbiana, a maior velocidade de trânsito pode estimular a eficiência de síntese protéica dos microrganismos, em razão da redução do gasto de energia para atividades de mantença desses microrganismos (Hespell \& Bryant, 1979; Firkins, 1996).

\section{Conclusões}

O perfil granulométrico da dieta exerceu efeito preponderante no trânsito das partículas dietéticas, observando-se que as dietas com maior proporção de partículas mais grosseiras foram as que promoveram maior tempo de permanência da digesta no trato gastrointestinal dos animais.

Da forma como o perfil granulométrico da dieta afetou os coeficientes de digestão da matéria seca, da matéria orgânica e da fibra, neste trabalho, percebe- 
se a necessidade de mais estudos com vistas à melhor compreensão das inter-relações entre o processamento dos ingredientes, o tamanho das partículas dietéticas e a digestibilidade das dietas.

\section{Literatura Citada}

ALDRICH, J.M.; MULLER, L.D.; VARGA, G.A. et al. Nonstructural carbohydrate and protein effects on rumen fermentation, nutrient flow, and performance of dairy cows. Journal of Dairy Science, v.76, p.1091, 1993.

ALLEN, M.S.; MERTENS, D.R. Evaluating constraints on fiber digestion by rumen microbes. Journal of Nutrition, v.118, n.1, p.261-270, 1988.

AMERICAN DAIRY SCIENCE ASSOCIATION - ADSA. A report: committee on classification of particle size in feedstuffs. Journal of Dairy Science, v.53, n.5, p.689-690, 1970.

ASSOCIATION OF OFFICIAL ANALYTICAL CHEMISTS AOAC. Official methods of analysis. 15.ed. Arlington: 1990. 1117p.

BEAUCHEMIN, K.A.; McALLISTER, T.A.; DONG, Y. et al. Effects of mastication on digestion of whole cereal grains by cattle. Journal of Animal Science, v.72, n.2, p.236-246, 1994.

BONDI, A. Nutricion animal. Zaragoza: Acribia, 1988. 546p.

BOWMAN, J.G.P.; FIRKINS, J.L. Effects of forage species and particle size on bacterial cellulolytic activity and colonization in situ. Journal of Dairy Science, v.76, n.7, p.1623, 1993.

BUXTON, D.R.; REDFEARN, D.D. Plant limitations to fiber digestion and utilization. Journal of Nutrition, v.127(suppl.), p.814-818, 1997.

CHENG, K.J.; McALLISTER, T.A. Compartmentation in the rumen. In: HOBSON, P.N.; STEWART, C.S. (Eds.) The rumen microbial ecosystem. 2.ed. London: Blackie Academic \& Professional, 1997. p.492-522.

CHURCH, D.C. The ruminant animal. Digestive physiology and nutrition. New Jersey: Prentice Hall, 1988. 564p.

DES BORDES, C.K.; WELCH, J.G. Influence of specific gravity on rumination and passage of indigestible particles. Journal of Animal Science, v.59, n2, p.470-475, 1984.

DIXON, R.M.; MILLIGAN, L.P. Removal of digesta components from the rumen of steers determined by sieving techniques and fluid, particulate and microbial markers. British Journal of Nutrition, v.53, n.2, p.347-362, 1985.

FIRKINS, J. Effects of feeding nonforage fiber sources on site of fiber digestion. Journal of Dairy Science, v.80, n.7, p.14261437, 1997.

FIRKINS, J. Maximizing microbial protein synthesis in the rumen. Journal of Nutrition, v.126, p.1347-1355, 1996 (Supplement).

FISHER, D.S.; BURNS, J.C.; POND, K.R. Kinetics of in vitro cell wall disappearance and in vivo digestion. Agronomy Journal, v.81, n.1, p.25-33, 1989.

FLINT, H.J.; FORSBERG, C.W. Polysaccharide degradation in the rumen: Biochemistry and genetics. In: ENGELHARDT, W.W.; LEONHARD-MAREK, S.; BREVES, G. et al. (Eds.). Ruminant physiology: Digestion, metabolism, growth and reproduction. Stuttgart: Enke, 1995. p.43-70.

HERRERA-SALDAÑA，R.; GOMES-ALARCON, R.; TORABI, M. et al. Influence of synchronizing protein and starch degradation in the rumen on nutrient utilization and protein synthesis. Journal of Dairy Science, v.73, n.1, p.142, 1991.

HESPELL, R.B.; BRYANT, M.P. Efficiency of rumen microbial growth: influence of some theoretical and experimental factor's

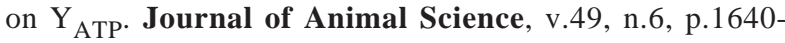
1659, 1979.

HOOVER, W.H.; STOKES, S.R. Balancing carbohydrates and proteins for optimum rumen microbial yield. Journal of Dairy Science, v.74, n.12, p.74, 1991.

ISHLER, V.; HEINRICHS, J.; VARGA, G. From feed to milk: understanding rumen function. Willard Building: Penn State Cooperative Extension, 1996. 52p. (Extension Circular, 422).

KASKE, M.; Von ENGELHARDT, W. The effect of size and density on mean retention time of particles in the gastrointestinal tract of sheep. British Journal of Nutrition, v.63, p.683, 1990.

LAMMERS, B.P.; BUCKMASTER, D.R.; HEINRICHS, A.J. A simple method for the analysis of particle sizes of forage and total mixed rations. Journal of Dairy Science, n.79, n.5, p.922-928, 1996.

LUCAS, H.L. Critical features of good dairy feeding experiments. Journal of Dairy Science, v.43, n.3, p.193-212, 1960.

MCCARTHY, R.D.; KLUSMEYER, T.H.; VICINI, J.L. et al. Effects of sources of protein and carbohydrate on ruminal fermentation and passage of nutrients to the small intestine of lactating cows. Journal of Dairy Science, v.72, p.2002, 1989.

MERTENS, D.R.; LOFTEN, J.R. The effects of starch on forage fiber digestion kinetics in vitro. Journal of Dairy Science, v.63, n.5, p. 1437, 1980.

MOONEY, C.S.; ALLEN, M.S. Physical effectiveness of the neutral detergent fiber of whole linted cottonseed relative to that of alfalfa silage at two lenghts of cut. Journal of Dairy Science, v.80, n.9, p.2052-2061, 1997.

NATIONAL RESEARCH COUCIL - NRC. Nutrient requirements of dairy cattle. 7.ed. Washington, D.C. National Academy of Science, 1988. 157p.

PELL, A.N.; SCHOFIELD, P. Computerized monitoring of gas production to measure forage digestion in vitro. Journal of Dairy Science, v.76, n.4, p.1063-1073, 1993.

POND, K.R., ELLIS, W., MATIS, C. Compartment models for estimating attributes of digesta flow in cattle. British Journal of Nutrition, v.60, n.2, p.571-595, 1988.

POPPY, D.P.; NORTON, B.W.; MINSON, D.J. et al. The validity of the critical size theory for particles leaving the rumen. Journal of Agricultural Science, v.94, n.2, p.275280, 1980.

RUSSELL, J.B.; O’CONNOR, J.D.; FOX, D.G. et al. A net carbohydrate and protein system for evaluating cattle diets: I. Ruminal fermentation. Journal of Animal Science, v.70, n.11, p.3551-3561, 1992.

SAUVANT, D. Rumen mathematical modelling. In: HOBSON, P.N.; STEWART, C.S. (Eds.) The rumen microbial ecosystem. 2. ed. London: Blackie Academic \& Professional, 1997. p.685-708.

SILVA, D.J. Análise de alimentos (Métodos químicos e biológicos). Viçosa, MG: Universidade Federal de Viçosa, 1990 165p.

SNIFFEN, C.J.; ROBINSON, P.H. Symposium: Protein and fiber digestion, passage, and utilization in lactating cow. Journal of Dairy Science, v.70, n.2, p.425-441, 1987. 
UDEN, P. The influence of leaf and stem particle size in vitro and sample size in sacco on neutral detergent fiber fermentation kinetics. Animal Feed Science and Technology, v.37, n.1, p.85, 1992.

UDEN, P.; COLUCCI, P.E.; Van SOEST, P.J. Investigation of chromium, cerium and cobalt as markers in digesta. Rate of passage studies. Journal of Science Food Agriculture, v.31, n.3, p.625-632, 1980.

UNIVERSIDADE FEDERAL DE VIÇOSA - UFV. SAEG Sistema de Análise Estatística e Genética. Versão 7.1. Viçosa, 1996. 150p. (Manual do usuário).

Van SOEST, P.J. Nutritional ecology of the ruminant. 2.ed. Ithaca: Comstock, 1994. 476p.

Van SOEST, P.J.; ROBERTSON, J.B.; LEWIS, B.A. Methods for dietary fiber, neutral detergent fiber, and nonstarch polysaccharides in relation to animal nutrition. Journal of Dairy Science, v.70, n.10, p.3583-3597, 1991.

VIEIRA, R.A.M. Modelos matemáticos para estimativa de parâmetros da cinética de degradação do capim-elefante (Pennisetum purpureum, Schum., cv. mineiro) em diferentes idades de corte. Viçosa, MG: Universidade Federal de Viçosa, 1995. 88p. Dissertação (Mestrado em Zootecnia) Universidade Federal de Viçosa, 1995.
WALDO, D.R.; SMITH, L.W. Model of cellulose disappearance from the rumen. Journal of Dairy Science, v.55, p.472, 1972.

WEIDNER, S.J.; GRANT, R.J. Altered ruminal mat consistency by high percentages of soybean hulls fed to lactating dairy cows. Journal of Dairy Science, v.77, n.2, p.522-532, 1994.

WILLIAMS, C.H.; DAVID, D.J.; IISMAA, O. The determination of chromic oxide in faeces samples by atomic absorption spectrophotometry. Journal of Agricultural Science, v.59, n.3, p.381-385, 1962.

YOKOYAMA, M.T.; JOHNSON, K.A. Microbiology of the rumen and intestine. In: CHURCH, D.C. (Ed.) The ruminant animal. Digestive physiology and nutrition. New Jersey: Prentice Hall, 1988. p.125-144.

Recebido em: 22/09/03

Aceito em: 02/07/04 